\title{
ENSINO DE CIÊNCIAS NA PERSPECTIVA MULTICULTURAL: REFLETINDO A EDUCAÇÃO CIENTÍFICA DENTRO DA TEORIA PÓS-COLONIAL
}

\author{
Dr. Hélio José Santos Maia \\ Dra. Maria Helena da Silva Carneiro
}

Faculdade de Educação, Universidade de Brasília (FE/UnB)

RESUMO: O artigo apresenta desafios ao
ensino de ciências frente à universalização da
educação e os enfoques multiculturais nas
diferentes áreas das ciências naturais. O
trabalho é parte de um estudo de
representação em conceitos científicos na
escola primária de Timor-Leste e tem como
principal problema, refletir e analisar como
modernamente se articulam pedagogicamente
as áreas das ciências no ensino básico em face
à convergência aos caminhos multiculturais.
Como metodologia utilizou-se de pesquisa
bibliográfica, investigação de caráter
qualitativo nas escolas primárias do Timor-
Leste e na sua formação de professores. Para o entendimento de abordagens culturais no ensino de ciências se recorreu à teoria póscolonial frente às concepções eurocêntricas e a diversidade de visões sobre a área. Entre as conclusões é perceptivel que os valores culturais refletem uma espécie de opinião étnica sobre a natureza e ao admiti-los no corpo dos conhecimentos científicos sem a devida separação destes, corre-se o risco de piorar o ensino de ciências naturais ao mistificar explicações regidas por leis naturais acerca dos mais variados fenômenos físicos e biológicos..

PALAVRAS-CHAVE: Ensino de Ciências, multiculturalismo, teoria pós-colonial.

\section{TEACHING SCIENCE IN A MULTICULTURAL PERSPECTIVE: REFLECTING SCIENTIFIC EDUCATION WITHIN POSTCOLONIAL THEORY}

ABSTRACT: The article presents challenges to the teaching of sciences regarding the universalization of education and multicultural approaches in the different areas of the natural sciences. The work is part of a study of representation in scientific concepts in the primary school of East Timor and has the as main problem, to reflect and analyze how pedagogically articulate the areas of science in basic education in the face of convergence to multicultural paths. As a methodology, we used bibliographic research, qualitative research in primary schools in Timor-Leste and in their teacher training. For the understanding of cultural approaches in science education, the postcolonial theory was used in the face of Eurocentric conceptions and the diversity of visions about the area. Among the conclusions, it is perceptible that cultural values reflect a kind of ethnic opinion about nature and admitting them in the body of scientific knowledge without proper separation of these, runs the risk of worsening the teaching of natural sciences by mystifying explanations governed by natural laws about the most varied physical and biological phenomena.

KEYWORDS: Science teaching, multiculturalism, post-colonial theory. 


\section{Educere "Educare \\ ReVISTA DE EduCACÃo}

Programa de Pós-Graduação em Educação - Universidade Estadual do Oeste do Paraná

\section{INTRODUÇÃO}

O processo de universalização da educação em ciências tem despertado interesse em diversas abordagens. Desde as puristas com a visão do ensino de ciências como sendo aquele que procura entender a aquisição humana começada na revolução científica nascida na Europa entre os séculos XVI e XVII, por meio de uma nova forma de pensar, de investigar a natureza e de estruturar a linguagem, cujas correntes principais foram o empirismo inglês e o racionalismo francês na figura dos filósofos cientistas Francis Bacon na Inglaterra e René Descartes na França, até os encaminhamentos modernos na abordagem do ensino científico em face ao multiculturalismo, em que os diversos povos, em função dos seus hábitos culturais, também possuem concepções explicativas da natureza e que devem ser consideradas no ensino de ciências.

Nota-se nestas duas abordagens incomensurabilidades que não as conciliam. O rigor metodológico das ciências clássicas não encontra eco na amplitude multicultural sobre a explicação para os fenômenos naturais. Enquanto a primeira procura ser universal e se adequar a rigorosas ponderações, a segunda se contenta com o metafórico, que por mais que seja adequada para explicar a natureza a sua volta na amplitude local e étnica, não é universal, e portanto, multiplica suas linguagens e explicações por quantos povos queiram se expressar.

De longas datas se observa tendências "politicamente corretas" de valorização cultural da multiplicidade de etnias, como se uma explicação cultural, sem base científica, também devesse ser considerada uma verdade validada, tornando o conhecimento científico ortodoxo, como mais um estilo de explicação entre outros tantos. Embora, nesta concepção, as linguagens não pareçam convergir para um ponto comum, há forte tendência ao caminho da incorporação de elementos multiculturais como conhecimento científico, gerando uma propriedade emergente que não é mais conhecimento científico e nem é 


\section{Educere "Educare \\ RevISTA De Educacão}

Programa de Pós-Graduação em Educação - Universidade Estadual do Oeste do Paraná

mais senso comum, é algo, que na consideração aqui expressa, piora a ciência e melhora o senso comum. Diante destas considerações, como modernamente se articulam pedagogicamente as áreas das ciências que são colocadas ao ensino básico, biologia, química, física e matemática em face à convergência aos caminhos multiculturais? Este artigo procura refletir como esses encaminhamentos convergem e o que pode se esperar dessa convivência.

\section{METODOLOGIA DA PESQUISA}

Essa pesquisa representa um fragmento dos estudos para tese de doutorado no campo da educação em ciências em contextos multiculturais, nascida da pesquisa no campo da representação de conceitos científicos na escola primária do Timor-Leste, país asiático fortemente atrelado a valores culturais autóctones, mas, procurando se inserir em um mundo com valores universais pautados na ciência hegemônica ocidental, sem abrir mão dos seus valores culturais plurais. Para sua consecução, foram estudados artigos e livros sobre o assunto, bem como, a observação e coleta de dados em loco na escola em Timor-Leste e na formação continuada de professores naquele país na área de Vida e Natureza (Biologia, Física e Química) no ano de 2007, da qual um dos autores do presente artigo participou como professor formador.

\section{CONCEPÇÕES SOBRE A NATUREZA: O UNIVERSAL FRENTE AO LOCAL}

O mundo conturbado que vivemos atualmente, representa um desafio ao entendimento ortodoxo que dele se tinha há algumas décadas. Muitos campos da atuação humana estão sendo revistos em busca de novos enfoques e referenciais. A educação de modo geral e a educação em ciências especificamente não têm sido deixadas de lado nessa busca. Há algum tempo trabalhos acadêmicos surgem com enfoques diferenciados para o ensino de ciências dentro de concepções que exploram uma diversidade de aspectos que 


\section{Educere "Educare \\ RevisTa de EduCAç̃o}

Programa de Pós-Graduação em Educação - Universidade Estadual do Oeste do Paraná

vão desde o feminismo (HOWES, 2002), passando por teoria crítica e pósestruturalistas voltadas para o conhecimento científico, educação e exercício de poder (BARTON; OSBORNE, 1998) e encaminhamentos que associam o uso da diversão como motivadores ao ensino de ciência (APPELBAUM; CLARK, 2001).

Porém, crescem em quantidade pesquisas e trabalhos acadêmicos voltados para o ensino de ciências dentro de perspectivas sócio-culturais (CARTER, 2004; LEMKE, 2001), ensino de ciências em interações bilíngue (MORTON, 2012) e em construtos da teoria pós-colonial, além da interculturalidade e educação científica (ABDULLAHI, 2007; VALLADARES, 2011), multiculturalismo na educação (BARAKOSKA, 2013), transculturalismo (AIKENHEAD, 2001; 2002; AIKENHEAD; JEGEDE, 1999). Ao que tudo indica, a preocupação nos trabalhos acadêmicos sobre ensino de ciências nesses vários aspectos, procura situar a existência de um conhecimento tido como científico em frente a uma profusão de outras abordagens sobre o mundo, há outras formas de conhecer que pertencem a círculos culturais etnicamente construídos, que servem como abordagem utilitarista para cada povo e que encerram suas verdades, ainda que conheçam versões de outras culturas que não lhes parecem verdadeiras. Essas versões alternativas são ainda mais problemáticas quando entram em confronto na sala de aula com as versões científicas para dado fenômeno no campo da biologia, da química e da física. O professor é desafiado, nos seus encaminhamentos pedagógicos a construir outra concepção em cima de repertórios culturais que os alunos já trazem de seu meio e que estão fortemente arraigados na sua estrutura cognitiva. Esse conflito é mais substancial ainda quanto a educação em ciências se dirige a sociedades fortemente apegadas aos seus valores autóctones culturais como se observa em países asiáticos como o Timor-Leste, por exemplo.

Em uma síntese sobre conhecimentos científicos na área das ciências em face a concepções de fenômenos na base cultural, Cobern e Loving (2001), contam uma história narrada pessoalmente por uma pesquisadora chamada 


\section{Educere "Educare \\ RevisTa de EduCAç̃o}

Programa de Pós-Graduação em Educação - Universidade Estadual do Oeste do Paraná

Gibson em 1996 que estava trabalhando em uma estação científica em floresta de uma ilha do Pacífico Sul. Ela conta que em uma conversa travada com um habitante autóctone da ilha, este mencionou que os ocidentais pensavam que somente eles sabiam por que o oceano aumenta e diminui de volume regularmente, atribuindo este efeito à influência da lua. Porém, estavam errados, pois o oceano aumenta e diminui seu volume em função das saídas e do retorno das grandes tartarugas marinhas dos seus ninhos na areia. Assim, o oceano diminui quando sua água corre para os ninhos vazios e aumenta seu volume quando a água é forçada a sair dos ninhos por ocasião do retorno das tartarugas. Dessa história podem-se extrair algumas questões que colocam em confronto dois modos de explicar o fenômeno natural das marés: um, seria o aceito pela ciência oficial ocidental como sendo o fenômeno regulado pela lua e outro, o alternativo contado pelo nativo como estando o fenômeno sobre a regulação do deslocamento das grandes tartarugas.

Ainda Cobern e Loving (2001), nos trazem questionamentos importantes sobre essa situação da história narrada acima: a explicação do nativo é científica porque ele tem conhecimento exato das marés do oceano que afetam a ilha? $\mathrm{Ou}$ não é científica porque sua explicação é cientificamente inapropriada? A ciência é universal porque sua avaliação científica padrão para explicar a ação das marés aplica-se a todas as ocorrências locais dos fenômenos de maré? Como o professor de ciências pode estruturar estratégias pedagógicas para introduzir anomalias nas concepções culturais que os alunos já trazem a respeito de fenômenos naturais como o relatado acima de modo a promover substancialmente mudanças conceituais? Respostas a esses questionamentos não são fáceis de enunciar. A atuação na educação científica em comunidades fortemente ligadas a valores culturais ancestrais representa um grande desafio pedagógico, pois, por mais consistentes que os argumentos da ciência pareçam, o poder da cultura representa um obstáculo epistemológico (BACHELARD, 2011) quase intransponível na aquisição de conceitos científicos. 


\section{Educere Educare \\ RevISTA De Educacão}

Programa de Pós-Graduação em Educação - Universidade Estadual do Oeste do Paraná

O conhecimento científico e seu ensino, dada a profusão de olhares das ciências humanas e sociais para o seu objeto, torna-o questionável nos aspectos que se ligam ao monismo das ciências ocidentais como a forma mais correta e verdadeira de conhecer a natureza e de certa forma de reconstruí-la por sua interferência. Com o avanço das investigações que se seguiram no campo da etnografia, da antropologia, as ciências naturais passam a ser tidas, nesse universo de saberes, como mais um componente em uma ecologia de saberes (SANTOS, 2010). Porém, saberes tradicionais com base em mitos e no sobrenatural, que sejam explicações alternativas à fenômenos perfeitamente explicados pela ciência, talvez não consigam resolver problemas de ordem mais complexas, que só a ciência consegue fazê-lo.

Ao considerar a escolarização nos padrões ocidentais para o ensino de ciências, o entendimento dos vários aspectos da cultura ocidental e suas multiplicidades sociais nas representações das crianças, por exemplo, em relação aos conceitos científicos é encontrado em muitos trabalhos, e aqui, para compreensão mais ampla sobre as representações das crianças em ciências, no que tange à concepções prévias, o principal suporte teórico pode ser oferecido pela teoria da aprendizagem significativa de Ausubel (2000). Por essa teoria, entende-se que uma nova informação é incorporada ao conhecimento já presente na estrutura cognitiva do aluno. Sendo esse conhecimento prévio, ao qual o autor referiu-se como subsunçor, uma espécie de ancoradouro onde os novos conhecimentos se ligarão, de modo não arbitrário e que o conhecimento a ser aprendido tenha relevância social e seja potencialmente significativo.

Mas, o processo de escolarização em ciência nos cânones ocidentais é capaz mesmo de promover mudanças conceituais que releguem saberes culturais a segundo plano? Ou conceitos científicos adquiridos vão integrar-se a uma estrutura mais semelhantes aos perfis epistemológicos de Bachelard? Nesse sentido, Bachelard (1979, p.24) vai falar que "a hierarquia dos conhecimentos se distribui de forma diversa segundo as utilizações" e essas diversas 


\section{Educere Educare \\ RevISTA De Educacão}

Programa de Pós-Graduação em Educação - Universidade Estadual do Oeste do Paraná

conceitualizações vão esboçar o perfil epistemológico de cada um. Evidencia ainda o autor que um perfil epistemológico se dirige a conceitos particulares:

Insistimos no fato de um perfil epistemológico dever sempre referir-se a um conceito designado, de ele apenas ser válido para um espírito particular que se examina num estádio particular da sua cultura. É esta dupla particularização que torna um perfil epistemológico interessante para uma psicologia do espírito científico. (p.25).

Mortimer (2000), usando a noção bachelardiana de perfil epistemológico em estudo sobre mudança conceitual, percebeu em estudantes a persistência de concepções prévias mesmo após o trabalho com os conceitos científicos, estes, ao invés de substituírem os entendimentos prévios, passavam a conviver com os mesmos. Nesse sentido, o autor postulou a hipótese de que "a aprendizagem de Ciências em sala de aula pode ser descrita como uma mudança do perfil conceitual do estudante, cujo novo perfil inclui também, mas não exclusivamente, as novas ideias científicas" (p.27).

O que possivelmente pode ocorrer na aquisição do conceito científico pela escolarização, é seu aporte em um subçunsor pré-existente na mente do indivíduo, como postula Ausubel, mas que, longe de tornar o subçunsor mais elaborado, promovendo até a obliteração do conceito primário, conforme a teoria, conviva com a ideia anterior e ganhe importância diferenciada de acordo com os contextos culturais. É certo que defender a ciência como sendo portadora de explicações racionais, de coerência e mais capacidade de resolver problemas, não é suficiente para generalizações em todos os campos da atuação humana. Há uma série de situações para as quais a ciência ainda não tem respostas definitivas, isso não significa que haja lacunas de conhecimento, outros saberes podem preenchê-las adequadamente, ainda que ditos não científicos. Nesse sentido, evocamos Merleau-Ponty (2004, p.5-6):

Trata-se de saber se a ciência oferece ou oferecerá uma representação do mundo que seja completa, que se baste, que se feche de alguma maneira sobre si mesma, de tal forma que não tenhamos mais nenhuma questão válida a colocar além dela. Não se trata de negar ou de limitar a ciência; 


\title{
Educere Educare \\ RevISTA De Educacão
}

Programa de Pós-Graduação em Educação - Universidade Estadual do Oeste do Paraná

\begin{abstract}
trata-se de saber se ela tem o direito de negar ou de excluir como ilusórias todas as pesquisas que não procedem como ela por medições, comparações e que não sejam concluídas por leis, como as da física clássica, vinculando determinadas consequências a determinadas condições. Não só essa questão não indica nenhuma hostilidade com relação à ciência, como é ainda a própria ciência, nos seus desenvolvimentos mais recentes, que nos obriga a formulá-la e nos convida a responder negativamente.
\end{abstract}

Trata-se de saber se a ciência oferece ou oferecerá uma representação do mundo que seja completa, que se baste, que se feche de alguma maneira sobre si mesma, de tal forma que não tenhamos mais nenhuma questão válida a colocar além dela. Não se trata de negar ou de limitar a ciência; trata-se de saber se ela tem o direito de negar ou de excluir como ilusórias todas as pesquisas que não procedem como ela por medições, comparações e que não sejam concluídas por leis, como as da física clássica, vinculando determinadas consequências a determinadas condições. Não só essa questão não indica nenhuma hostilidade com relação à ciência, como é ainda a própria ciência, nos seus desenvolvimentos mais recentes, que nos obriga a formulá-la e nos convida a responder negativamente.

\section{A PANACEIA da TEORIA Pós-COLONIAL NA EDUCAÇÃo, UMA FUNDAMENTAÇÃO TEÓRICA}

Para o entendimento de abordagens culturais no ensino de ciências se recorre aqui à teoria pós-colonial. Muita controvérsia paira sobre o termo "póscolonial", admitindo-se uma variedade de interpretações e caminhos a seguir na busca da melhor abordagem para exprimir o encaminhamento que sirva de base para um dado estudo específico. Certamente o termo procura estabelecer uma espécie de abrangência que encerre uma gama de termos desgastados pelo uso e restritos pela empregabilidade, tais como "imperialismo", "crítica terceiromundista", "neocolonialismo e práticas culturais de resistência" e "geopolítica do 


\section{Educere "Educare \\ RevisTa de EduCAç̃o}

Programa de Pós-Graduação em Educação - Universidade Estadual do Oeste do Paraná

intercâmbio cultural" (SHOHAT, 2000). O desgaste dos encaminhamentos associados ao termo "terceiro-mundista",

ajuda a explicar o atual entusiasmo pelo termo "pós-colonial", uma nova designação para os discursos críticos que tematizam as questões derivadas das relações coloniais e suas sequelas, cobrindo um período histórico amplo (incluindo o presente)." (SHOHAT, 2000, p.105).

É certo que encarar toda a discussão sobre a literatura, educação, política, economia e outros setores na abrangência da teoria pós-colonial, como pertencendo a um lugar que contém todos os que saíram da dominação colonial, é colocar em um mesmo pacote, países como a Austrália, os Estados Unidos, junto com Índia, Brasil, Timor-Leste e tantos outros. Apesar de o pós-colonial englobar todos os elementos culturais surgidos posteriormente à colonização europeia, entende-se aqui, que os europeus remanescentes e seus descendentes diretos nas ex-colônias, continuaram na hegemonia do comando em grande parte das ex-colônias que se tornaram países independentes e terminaram também por influenciar os campos da educação e da literatura, para mencionar apenas esses dois. Desse modo, ao buscar o conhecimento cultural dos povos que foram dominados no sistema colonial, nos referiremos à cultura das populações autóctones que tiveram a sobrevivência dos conhecimentos culturais conquistados ao longo da sua história, ameaçados pela dominação estrangeira, e até, suplantados por esta. Assim, no rastro do pós-colonialismo, surgem à luz a importância da sua consideração, discussão e como podem fazer parte de um universo, que não obstante globalizado, é multicultural.

Embora vivamos em um mundo em que se diz procurar estreitar as relações humanas a nivel global, o contraste com as reivindicações das identidades dos diversos povos, clama pela sobrevivência das individualidades culturais, o que é paradoxal no aspecto da globalização. Dessa forma, possivelmente existam forças contraditórias atuando em diferentes campos, incluindo a educação e a oposição entre uma escolarização mundial uniforme e uma escolarização plural e cultural, expressão da dicotomia do local versus 


\section{Educere "Educare \\ REVISTA DE EduCACÃo}

Programa de Pós-Graduação em Educação - Universidade Estadual do Oeste do Paraná

global. Ao discutirmos escolarização sob a ótica da globalização, em que os saberes hegemônicos se sobrepõem aos saberes culturais dos povos que sofreram processo de colonização, é inevitável a utilização da Teoria Pós-Colonial como referencial teórico.

O processo de dominação estabelecido no período de colonização encontrou na educação uma via de destruição dos valores e dos conhecimentos tradicionais de muitos povos, e o ensino de ciência, ainda que em épocas em que a própria ciência se estabelecia, parece ter sido muito satisfatória para essa dominação em um colonialismo mais tardio. Os professores pautados pela valorização do conhecimento científico promovem nos estudantes um sentimento de inferioridade acerca dos seus próprios conhecimentos tradicionais (NORBERG-HODGE, 2009). Possivelmente, estes conhecimentos terminam sendo relegados ao campo do pitoresco, do senso comum, sem valor prático na resolução de problemas, sobretudo, quando se trata de populações autóctones dominadas em seu território por nações imperialistas ocidentais e que, portanto, com valores culturais implantados na ciência.

Aikenhead (2001) menciona intensa lealdade dos professores de ciências aos valores associados ao cientificismo, ao estabelecer os conhecimentos científicos como não-humanistas, puramente racionais e empíricos, universal, impessoal, socialmente estéril e livre de vulgarização, dogma, julgamentos, ou valores culturais humanos. O trabalho do professor de ciência parece centrar-se no esforço de fazer os estudantes valorizarem o conhecimento científico de tal modo a promover uma espécie de aculturação em que o currículo das ciências estabeleça definitivamente nos estudantes os valores da ciência ocidental.

Por outro lado, a aculturação dos estudantes que promove a sua inserção nos valores das ciências ocidentais, também os insere, sobretudo, no universo do uso das tecnologias digitais, e estas passam a exercer grande influência em suas vidas, instrumentalizando-os para a discussão sobre temas relacionados às próprias ciências e tecnologia. A alienação dos estudantes em relação à aceitação dos valores ocidentais, especialmente nas ciências, diminui o capital Revista Educere Et Educare, Vol. 13, N. 30, nov./dez. 2018. Ahead of Print. 


\section{Educere "Educare \\ RevisTa de EduCAç̃o}

Programa de Pós-Graduação em Educação - Universidade Estadual do Oeste do Paraná

cultural para sua participação eficaz nas sociedades ocidentais ou por estas influenciadas. Para Aikenhead (2001), o problema da alienação é mais agudo para estudantes aborígenes cujas visões de mundo, identidades e línguas maternas criam um fosso cultural ainda maior entre si e as ciências da escola.

Os estudos sobre o ensino de ciência na perspectiva sócio-cultural, que levantam pontos de vista críticos, sociológicos, históricos, políticos e socioambientais sobre a construção do conhecimento científico e sua coexistência com outros sistemas de conhecimento tão variados e múltiplos quanto as culturas humanas, têm desafiado a concepção da ciência ocidental tradicional, para a qual a ciência está livre de valores, o conhecimento é objetivo, erigido em verdades universais (CARTER, 2008). Assim, o campo da teoria póscolonial representa uma fonte inquestionável de suporte nestas discussões.

Destarte, sem sombra de dúvida, qualquer trabalho que considere a Teoria Pós-Colonial, verá como momento fundador o trabalho do palestino, radicado nos Estados Unidos, Edward Said, chamado "Orientalismo", cuja primeira edição é de 1976 (SAID, 2008). Neste trabalho, que amplia concepções anti-coloniais de Frantz Fanon em sua obra Black skins, White masks de 1968 (FANON, 2008), Said, ao analisar a literatura produzida até então sobre o Oriente, percebe intenções preconceituosas acerca da cultura Oriental, ao tempo que se enaltecia, por contraste, a superioridade da cultura Ocidental. Trabalhos acadêmicos de maior complexidade foram desenvolvidos na década de 1990, sobretudo por meio dos estudos pós-coloniais de Homi K. Bhabha (BHABHA, 2001) e do antropólogo Arjun Appadurai (APPADURAI, 1996).

Com relação ao ensino de ciências com uma abordagem que utiliza elementos da Teoria Pós-Colonial, a exemplo do multiculturalismo, se destacam os trabalhos realizados por pesquisadores em comunidades tradicionais (AIKENHEAD, 2001; ALFRED, 2009; BATTISTE, 1998; HAMMERSMITH, 2009; WATERFALL, 2002). Diante da ênfase que estes estudos têm demonstrado no campo do multiculturalismo e do transculturalismo, destacam-se nesse domínio os trabalhos de Lyn Carter (CARTER, 2004; 2005; 2006; 2011), em que procura 


\section{Educere Educare \\ ReVISTA DE EduCACÃo}

Programa de Pós-Graduação em Educação - Universidade Estadual do Oeste do Paraná

discutir a valorização dos saberes das culturas de povos tradicionais no ensino de ciência em abordagens universais pautadas na uniformidade eurocêntrica.

Nos estudos realizados em comunidades tradicionais (ALFRED, 2009; BATTISTE, 1998; HAMMERSMITH, 2009; WATERFALL, 2002), percebe-se a influência e os efeitos da colonização, bem como das políticas imperialistas que corroem o conhecimento tradicional desses povos, por meio de uma educação em língua do colonizador e com base eurocêntrica. Battiste (1998), por exemplo, pesquisando comunidades aborígenes do Canadá, discute a necessidade do conhecimento aborígene ser contemplado em um currículo transformado e por meio das suas línguas, abraçando a rica diversidade de conhecimento desses povos, proporcionando a consciência necessária para o respeito e proteção dos aborígines.

O que se percebe ainda nestes estudos, relaciona-se à busca de alternativas de uma educação multicultural, em que as visões das populações tradicionais entrem nos currículos escolares a serem trabalhados nestas comunidades. Sobre isso, questões importantes surgem, tais como: (1) o conhecimento científico sobre os fenômenos da natureza são isentos de aspectos culturais? (2) Haveria uma tendência na pesquisa atual no campo do ensino de ciências, a uma sociologia da ciência que busca artificialmente valorizar aspectos culturais sob o conhecimento científico? (3) Ou há de fato a necessidade de incorporar valores culturais às bases do conhecimento científico ocidental produzido? E se assim o for, existiria uma biologia, uma química ou uma física alternativa e ao quê isso levará?

Com relação à primeira questão feita no parágrafo anterior (1), contribuição importante para uma reflexão sobre a mesma é oferecida por Bishop (2003), que ao analisar o papel da educação matemática ocidental, salienta que de todos os temas que foram impostos a alunos nas escolas coloniais, sem dúvida, pode-se considerar que o menos carregado culturalmente foi a matemática. A matemática de alguma forma sempre foi percebida como universal e, portanto, livre de cultura. Assim, concebeu-se a matemática, em Revista Educere Et Educare, Vol. 13, N. 30, nov./dez. 2018. Ahead of Print. 


\section{Educere "Educare \\ RevisTa de EduCAç̃o}

Programa de Pós-Graduação em Educação - Universidade Estadual do Oeste do Paraná

tempos coloniais e até nossos dias, como um fenômeno culturalmente neutro diante de outras formas do imperialismo,o que não ocorria com o ensino de História ou de Religião, por exemplo, pois ao serem ensinadas essas disciplinas abordavam a história e a religião do colonizador e não a dos colonizados. Todavia, o autor salienta que ideias matemáticas, como quaisquer outras ideias, são construções humanas, tendo, portanto, uma história cultural. Assim, a matemática que a maioria das pessoas aprende na escola contemporânea não é a única matemática que existe. Para reforçar essa afirmação, exemplifica citando que existem muitos sistemas de contagens diferentes no mundo, como em Papua Nova Guiné onde foram documentados cerca de 600 destes sistemas, contendo vários ciclos de números, nem todos de base decimal. Então, como ocorre com a matemática, que a primeira vista é tida como isenta de cultura, mas, representa apenas mais uma forma conhecimento construída culturalmente, o conhecimento produzido pela ciência ocidental também representa a produção de uma cultura.

Para a segunda questão (2), busca-se reflexão nas abordagens sobre a natureza da ciência. Estas colocam em discussão tipos diferentes de tratamentos, as de viés internalistas e aquelas de caráter externalistas. A sociologia da ciência, a analisa do pondo de vista externalista, ou seja, são considerados no entendimento da natureza das ciências, valores sociais, culturais, políticos e até mesmo questões econômica para entender-se o fazer científico. Essa visão se consubstancia no pós-guerra, com o advento da guerra fria e dos problemas daí advindos, levando sociólogos, historiadores e filósofos a se debruçarem sobre as questões científicas, minimizando o entendimento da ciência em seu caminho positivista no estabelecimento do saber conceitual sobre os fenômenos da natureza, o que se enquadra no percurso internalista. Não obstante isso, o processo de ensinar ciência, sobretudo no ensino básico, ainda centra-se nos aspectos internalistas. Procura-se ensinar o conceito do produto da ciência, atemporal, descontextualizado, imparcial, isento de subjetividade, o que diminui os aspectos externalista no ensino nesse nivel. Possivelmente isso Revista Educere Et Educare, Vol. 13, N. 30, nov./dez. 2018. Ahead of Print. 


\section{Educere "Educare \\ REVISTA DE EduCACÃo}

Programa de Pós-Graduação em Educação - Universidade Estadual do Oeste do Paraná

se deve ao fato dos docentes entenderem a abordagem externalista da ciência, como inferências das ciências humanas e, portanto, passíveis da subjetividade e da criatividade imaginativa não admitida para as ciências naturais nesse tipo de concepção.

Já a terceira questão (3), de caráter externalista, busca resposta no campo das ciências humanas, especialmente da sociologia, da história e filosofia das ciências, admitindo considerações de natureza cultural como intervenientes na construção do entendimento científico do mundo. Estando nesse campo, uma fronteira tênue a separar senso comum de conhecimento científico. As perspectivas de análise dos currículos de ensino de ciências têm incorporado novos caminhos que podem em si, conter falácias e modismos, possivelmente pervertendo o processo de ensinar ciências. Resta analisar ao que serve essas abordagens. Quando se fala nesses novos enfoques, a tendência atual é evidenciar o multiculturalismo e o transculturalismo, abordagens contidas também no "guarda-chuva" que representa a teoria pós-colonial. O primeiro traz em sua máxima concepção a valorização da multiplicidade cultural e vias para o respeito e a preservação de todas nos currículos. O segundo aponta a necessidade de entender as transformações presentes na junção de culturas diferentes, como uma nova propriedade emergente nessas interações. Todavia, antes de empreender uma jornada nesse caminho, é necessário o entendimento mais aprofundado sobre o assunto. O ensino de ciência estabelecido é visto nessa perspectiva como um saber tradicional, dominante, que traz o traço do imperialismo das nações hegemônicas ocidentais capitalistas, e a ciência que é ensinada apresenta o caráter cultural do dominador e seu modo de se difundir e de pensar o mundo, o concebe mais como um mercado consumidor, que para esse propósito, deve ser modelado pelos valores do conhecimento ocidental, aí incluso a ciência, do que como um conhecimento libertador. A educação nessa análise é vista como uma forma de dominar pela homogeneização povos diferentes, suplantando suas culturas, fragilizando suas resistências em beneficio do estabelecimento dos seus propósitos. 


\section{Educere "Educare \\ RevISTA De Educacão}

Programa de Pós-Graduação em Educação - Universidade Estadual do Oeste do Paraná

Mas, não seria essa concepção de minimizar a importância do fazer ciências naturais, sobretudo, aí compreendendo também a sua divulgação, nos modelos vigentes, uma tentativa de transformar as ciências naturais como algo menor em face a outros saberes? O saber científico acumulado, que trouxe respostas tecnológicas para a resolução de inúmeros problemas e também para a criação de outros tantos, deve ter outra forma de ser ensinada? Ou se busca um ensino que incorpore com o mesmo peso da importância do ensino de ciências, outros saberes que podem ser compreendidos como formas alternativas de verdades perfeitamente assimiláveis? Aí incluso saberes metafísicos do sobrenatural, do mítico-esotérico, do religioso, do folclórico, enfim, do senso comum multicultural.

Nesse sentido, as abordagens multiculturais parecem ser uma falácia que acentuam ainda mais a separação entre uma educação cognitiva que forma indivíduos para compreender a ciência e sua natureza, e outra educação que trabalha indivíduos para compreender o mundo em caminhos alternativos de concepções vinculadas às suas verdades culturais. Nesse entendimento, percebe-se a nítida dicotomia entre o sucesso e o fracasso que podem advir do tipo de educação que se pratica. É perceptivel em muitos discursos a existência de entendimentos do "politicamente correto" que em última análise, recriminam as conquistas da ciência como sendo perigosas, maléficas, potencialmente destruidoras, agressivas ao meio ambiente, para citar apenas algumas. Desse modo, um ensino de ciências que incorpore essa compreensão negativa, longe de buscar estabelecer a compreensão de processos e conceitos dos avanços da ciência, apenas ensinam as pessoas a reagir e recusar esses avanços. Trazendo essa compreensão para um tema atual como exemplificação na sala de aula, muitas vezes quando o assunto é "alimentos transgênicos", o professor dispensa seu tempo de sala de aula abordando os potenciais maleficios dessa conquista das ciências biológicas, do que na compreensão de todos os processos envolvidos e conceitos necessários para o estabelecimento da conquista científica em si, tais como o entendimento dos avanços advindo da engenharia genética que permite a 


\title{
Educere Educare \\ RevISTA De Educacão
}

Programa de Pós-Graduação em Educação - Universidade Estadual do Oeste do Paraná

utilização de plasmídeo $^{1}$ na multiplicação e inserção de genes especiais em outros seres. Isso é a evidência da luta travada entre concepções externalistas versus internalistas da ciência no estabelecimento de conceitos e a abordagem pedagógica do docente pode contribuir para um caminho ou para o outro.

A primeira premissa a ser tratada quando o assunto é multiculturalismo refere-se ao entendimento das diversas culturas que devem ser olhadas e respeitadas dentro do processo educativo. Nesse sentido, o multiculturalismo, pode ser entendido também como um "caldeirão" de considerações diversas e muitas vezes divergente de posicionamentos e opiniões com base nas particularidades culturais. Todavia, quando se procura aplicar essa aceitação multicultural com base nas múltiplas opiniões afeitas à abordagem multiculturalista para o ensino de ciências, pode-se recorrer ao entendimento de Bachelard $(2011$, p.18) que de certa forma, traduz o purismo internalista que deve prevalecer no que se refere às ciências. Para ele,

\begin{abstract}
A ciência, tanto por sua necessidade de coroamento como por princípio, opõe-se absolutamente à opinião. Se, em determinada questão, ela legitimar a opinião, é por motivos diversos daqueles que dão origem à opinião; de modo que a opinião está, de direito, sempre errada. A opinião pensa mal; não pensa: traduz necessidades em conhecimentos. Ao designar os objetos pela utilidade, ela se impede de conhecê-los. Não se pode basear nada na opinião: antes de tudo, é preciso destruí-la. Ela é o primeiro obstáculo a ser superado. Não basta, por exemplo, corrigi-la em determinados pontos, mantendo, como uma espécie de moral provisória, um conhecimento vulgar provisório. O espírito científico proíbe que tenhamos uma opinião sobre questões que não compreendemos, sobre questões que não sabemos formular com clareza.
\end{abstract}

Considerando que os valores culturais refletem uma espécie de opinião étnica sobre a natureza, sem o rigor da ciência clássica, ao admiti-los no corpo dos conhecimentos científicos sem a devida separação destes, corre-se o risco de piorar ainda mais o ensino de ciências naturais ao mistificar explicações regidas por leis naturais acerca dos mais variados fenômenos físicos e biológicos, fortalecendo as concepções alternativas dos estudantes em detrimento dos conhecimentos científicos que se deseja estabelecer. 


\section{Educere "Educare \\ REVISTA DE EduCACÃo}

Programa de Pós-Graduação em Educação - Universidade Estadual do Oeste do Paraná

\section{CONSIDERAÇÕES FINAIS}

As diferentes posturas docentes no ensino das variadas ciências tais como a biologia, física e química, bem como as vias pedagógicas para sua consecução refletem o tipo de formação básica e continuada dispensada a estes professores. Nesse sentido, resta à pesquisa neste campo se debruçar sobre as tendências do ensino no campo da educação comparada em ciências praticadas pelos diferentes países e observar nestes o reflexo do ensino nas suas sociedades. Possivelmente se vislumbrará diferenças marcantes no que se refere à qualidade de vida frente aos avanços tecnológicos em função de como a educação em ciência é tratada.

A importância da valorização cultural dos povos é inegável para a reafirmação das identidades culturais nacionais, mas para isso, muitas áreas do conhecimento já dão o devido suporte como as literaturas, sociologia, antropologia, história, enfim, há muito mais exposição a valores culturais nos currículos do que o contrário. Assim, eivar o ensino de ciências nos moldes clássicos com elementos culturais, onde estes valores pendem para o sobrenatural das explicações alternativas, parece servir ao conformismo que atrelam sociedades ao atraso, sob a égide de valorização cultural. Este, possivelmente, não é o papel das ciências naturais, muito pelo contrário, ensinar ciências naturais com seus encaminhamentos pedagógicos adequados, com vista à formação do indivíduo para opinar frente aos grandes desafios que se impõe à sociedade, é empoderá-lo com o conhecimento necessário para atuar em beneficio da sociedade como um todo objetivando a melhoria da qualidade de vida.

Ainda que a abordagem pós-colonial estabeleça múltiplas vozes para postular a valorização cultural dos povos, não se pode negar a importância das ciências modernas como vias de acesso a conquistas que nenhum outro sistema de conhecimento pôde constituir. Ninguém em sã consciência se sentiria confortável e seguro ao saber que em um avião, com toda sua complexidade 


\section{Educere Educare \\ ReVISTA de EduCAC̄̃o}

Programa de Pós-Graduação em Educação - Universidade Estadual do Oeste do Paraná

tecnológica em pleno vôo, onde fosse passageiro, estivesse como piloto um xamã de uma nobre tribo tradicional sem experiência alguma em aviação, mas com larga experiência no mundo espiritual. De modo semelhante, há de se convir que ninguém se sentiria tranquilo perdido em uma floresta tropical densa sendo guiado por um piloto de avião que entende tudo de GPS e localização geográfica mediada por máquinas, mas nada sobre como se localizar em um floresta densa. Conhecimentos diversos têm funções diversas e podem conviver um com o outro. 


\section{Educere Educare \\ ReVISTA DE EduCACÃo}

Programa de Pós-Graduação em Educação - Universidade Estadual do Oeste do Paraná

\section{REFERÊNCIAS BIBLIOGRÁFICAS}

ABDULLAHI, I. Diversity and intercultural issues in library and information science (LIS) education. New Library World, v. 108, n. 9/10, p. 453-459, 2007.

AIKENHEAD, G. Integrating Western and Aboriginal Sciences: Cross-Cultural Science Teaching. Science Education, 2001, vol. 31, no. 3, pp. 337-355.

Cross-cultural science teaching: Rekindling traditions for Aboriginal students. Canadian Journal of Math, Science \& Technology Education, v. 2, n. 3, p. 287-304, 2002.

AIKENHEAD, G.; JEGEDE, O. J. Cross-cultural science education: A cognitive explanation of a cultural phenomenon. Journal of research in science teaching, v. 36, n. 3, p. 269-287, 1999.

ALFRED, T. Colonialism and state dependency. Journal de La santé autochtone, v. 5, p. 42-60, 2009.

APPADURAI, A. Modernity At Large: Cultural Dimensions of Globalization. University of Minnesota Press, 1996.

APPELBAUM, P.; CLARK, S. Science! Fun? A critical analysis of design/content/evaluation. Journal of Curriculum Studies, v. 33, n. 5, p. 583600, 2001.

AUSUBEL, D.P. The Acquisition and Retention of Knowledge: A Cognitive View. Dordrecht, Netherlands: Kluwer Academic Publisher, 2000.

BACHELARD, G. A filosofia do não. Coleção Os Pensadores. São Paulo: Abril Cultural, 1979.

BACHELARD, G. A formação do espirito científico: contribuição para uma psicanálise do conhecimento. Rio de Janeiro: Contraponto, 2011.

BARAKOSKA, A. Multiculturalism as important characteristic of contemporary education. International Journal of Cognitive Research in Science, Engineering and Education (IJCRSEE), v. 1, n. 1, p. 51-56, 2013.

BARTON, A. C.; OSBORNE, M. D. Marginalized Discourse and Pedagogies: Constructively Confronting Science for All. Journal of Research In Science Teaching, v. 35, n 4, p. 339-340, 1998.

BATTISTE, M. Enabling the Autumn Seed: Toward a Decolonized Approach to Aboriginal Knowledge, Language, and Education. Canadian Journal of Native Education, v. 22, n. 1, p. 16, 1998.

BHABHA, H. K. O Local da Cultura. Belo Horizonte: Editora UFMG, 2001. 


\section{Educere Educare \\ ReVISTA DE EduCACÃo}

Programa de Pós-Graduação em Educação - Universidade Estadual do Oeste do Paraná

BISHOP, A. Western Mathematics: The Secret Weapon of Cultural Imperialism. In: ASHCROFT, B.; GRIFFITHS, G.; TIFFIN, H. The post-colonial studies reader. London: Routledgeand Taylor \& Francis e-Library, 2003.

CARTER, L. Gathering in threads in the insensible global world: the wicked problem of globalisation and science education. Cult. Stud. of Sci. Educ, 6:1-12, 2011.

Sociocultural influences on science education: Innovation for contemporary times.Science Education, v. 92, n. 1, p. 165-181, 2008.

Postcolonial Interventions Within Science Education: Using postcolonial ideas to reconsider cultural diversity scholarship. Educational Philosophy and Theory, vol. 38, $\mathrm{n}^{\circ}$ 5, 2006.

A Place for Alternative Readings: Can They Be of Use? Responding to Comments on "Thinking Differently About Cultural Diversity: Using Postcolonial Theory to (Re)read Science Education". Wiley Inter Science, 2005.

Thinking differently about cultural diversity: Using postcolonial theory to (re) read science education. Science Education, v. 88, n. 6, p. 819-836, 2004.

COBERN, W.W.; LOVING, C.C. Defining" science" in a multicultural world: Implications for science education. Science Education, v. 85, n. 1, p. 50-67, 2001.

FANON, F. Black skins, white masks. New York: Grove Press, 2008.

HAMMERSMITH, J. A. Converging indigenous and western knowledge systems: Implications for tertiary education. 2009.

HOWES, E. V. Connecting girls and science: Constructivism, feminism, and science education reform. Teachers College Press, 2002.

LEMKE, J. L. Articulating communities: Sociocultural perspectives on science education. Journal of research in science teaching, v. 38, n. 3, p. 296-316, 2001.

MERLEAU-PONTY, M. Conversas, 1948. São Paulo: Martins Fontes, 2004.

MORTIMER, E.F. Linguagem, e formação de conceitos no ensino de ciências. Belo Horizonte: Editora UFMG, 2000.

MORTON, T. Classroom talk, conceptual change and teacher reflection in bilingual science teaching. Teaching and Teacher Education, v. 28, n. 1, p. 101-110, 2012. 


\section{Educere Educare \\ ReVISTA DE EduCAC̄̃o}

Programa de Pós-Graduação em Educação - Universidade Estadual do Oeste do Paraná

NORBERG-HODGE, H. Ancient Futures: Lessons from Ladakh for a Globalizing World. San Francisco, CA: Sierra Club Books, 2009.

SANTOS, B. D. S. A Non-Occidentalist West?: Learned Ignorance and Ecology of Knowledge. Theory, Culture \& Society, v. 26, n. 7-8, p. 103-125, 2010.

SAID, E. W. Orientalismo. Barcelona: Debate Editorial, 2008.

SHOHAT, E. Notas sobre 1o "postcolonial". In: Estuidio postcoloniales: ensayos fundamentales. Madrid: Traficantes de Sueños, 2008.

< http://issuu.com/gonzalodxrex/docs/mezzadra_s._edit._._estudios_post?e= 2087885/12924295>.

VALLADARES, L. La educación científica intercultural y El enfoque de las capacidades. Revista iberoamericana de ciência tecnologia y sociedad, v. 6, n. 16, p. 39-69, 2011.

WATERFALL, B. Native people and the social work profession: A critical exploration of colonizing problematic and the development of decolonized thought. The Journal of Educational Thought (JET)/Revue de la Pensée Educative, p. 149-166, 2002.

${ }^{1}$ Moléculas de DNA bacteriano independente do DNA dos cromossomos, que tem replicação autônoma. É implicado como um dos mecanismos que justifica a resistência bacteriana a antibióticos. Tem sido largamente usada na engenharia genética na tecnologia de transgênicos. (Nota dos autores).

Recebido em: 16/02/2018

Aprovado em: 26/07/2018 